\title{
A comparison of two scales of body condition scoring in Hereford $x$ Friesian beef breeding cows
}

\author{
Institute of Veterinary, Animal and Biomedical Sciences, Massey University, Palmerston North \\ S.T.Morris@massey.ac.nz
}

\begin{abstract}
Condition scoring is an easy to use management tool that can assist farmers to monitor their feeding regimes, allowing both better feed and animal management. The relationship between two commonly used condition score systems utilised by New Zealand beef cattle farmers was investigated. Results indicated that there is not a simple relationship between the $0-5$ condition score and the 1-10 score system. The relationship varies throughout the year and a single calibration equation should not be used when converting data from one system to the other. Despite this, the use of condition scoring in beef cow herds should be encouraged and operators can use either system, as long as care is taken when interpreting data from publications using different scales.
\end{abstract}

Keywords: beef cows, cattle, condition score, liveweight

\section{Introduction}

The body reserves of both beef and dairy cows are often an important source of energy at critical stages of the production cycle. Interpretation of liveweights can be difficult owing to differences in mature size of animals, stage of pregnancy, and gut fill. The introduction of a system of scoring body condition in sheep by Jefferies (1961) enabled farmers and extension workers to assess body reserves without the need for weighing, and it has been adopted by Lowman et al. (1976) for use in beef cattle. Farmers, advisors and researchers use body condition score to assess body reserves at critical stages of the production cycle and as an aid towards optimising nutritional management and reproductive efficiency. For example, numerous studies have indicated that cow condition at calving is important in determining postpartum interval, and thus re-breeding rate (Nicol \& Hughes 1980; Richards et al. 1986; Selk et al. 1988; DeRouen et al. 1994). The condition score technique is easily learned, requires no equipment and, although it is a subjective system it has been shown to give reliable results when related to subcutaneous fat cover (Wright \& Russel, 1984).

New Zealand dairy farmers generally use the condition score 1-10 method described by Holmes et al. (1987) (where 1 is emaciated and 10 a grossly obese animal). However, in reality many people only use five points of this scale (ie 3-7). In the beef industry a mixture of the
1-10 scale system and a $0-5$ scale system are used. The $1-10$ scale is based on the dairy system, while the $0-5$ scale is adapted from the Scottish 6 point scale $(0=$ thinnest, 5 = fattest) of Lowman et al. (1976). To further add to this confusion the USA favours a scoring range of 1 - 9 ( 1 being very thin and 9 extreme fatness) (Corah 1989). There are a few published reports quoting condition scores of beef bred cows in the New Zealand literature, and of these there is a mixture of both the 1-10 score scale (Reardon et al. 1978; Nicoll 1979; Morris et al. 1985; Smeaton et al. 2000) and the 0-5 scale (Gilmour 1998; Morris \& Hughes 1999).

The aim of the study reported here was to investigate the relationship between the 1-10 (CS1-10) condition score scale and the 0-5 (CSO-5) condition score scale in a herd of mixed aged Hereford $x$ Friesian beef cows. Knowledge of this relationship should enable consultants and farmers to convert information available from either condition score systems they use. Cow liveweights were also measured in an attempt to develop a relationships between cow liveweight change and condition score.

\section{Methods}

Two hundred and nineteen mixed age Hereford cross Friesian cows mated to Charolais bulls were used in the study. The mating period was from 20 November to 11 January 2001 (52 days). The cows were condition scored by two independent operators with the operator for the beef system (CS 0-5) having 10 years experience and the dairy system (CS1-10) having 8 years experience. Condition score has been shown to have high repeatability within user (Nicoll 1979), but not between users therefore only one experienced operator was used for each system. Cow condition score were taken at mid winter (June) (on average at 6 months pregnant), pre-calving ( 8 months pregnant August), mating (November) and weaning (March). Cow liveweights (maximum of 2 hours offpasture) were taken at the same time as condition scores. Calf liveweights were taken at birth, day 60 of lactation and at weaning (mean age 177 days). Cows were managed as described by Morris \& Hughes (1999). The relationships between the $\mathrm{CS}(1-10)$ and $\mathrm{CS}(1-5)$ condition score systems, condition score and liveweight, and condition score and liveweight change were calculated by linear regression analysis after initially checking for non lineararity using Minitab (Minitab 1998). 


\section{Results}

Of the 219 cows mated in 2000 and present at calving in 2001, 209 cows calved and 201 successfully reared a calf to weaning. Average calf birth, day 60 and weaning liveweights \pm standard errors were $39.9 \pm 0.4,111.9 \pm$ $1.5,240.4 \pm 2.3 \mathrm{~kg}$, respectively. Cow liveweight and condition scores at the various stages of the production cycle are shown in Table 1.

The relationship between the two condition score scales at various times of year are shown in Table 2. A calibration table to enable direct comparisons between the two scoring systems at various times of the year using the relationships shown in Table 2 are displayed in Table 3. The "All data" column in Table 3 gives the aggregate of all time points.

The linear relationship between both condition score $(0-5)$ and condition score (0-10) and liveweight was represented by the equations

$$
\begin{aligned}
& \mathrm{CS}(0-5)=0.0070 \times \mathrm{LW}-1.07, \mathrm{R}^{2}=0.4669 \\
& \mathrm{CS}(0-10)=0.0058 \times \mathrm{LW}+1.61, \mathrm{R}^{2}=0.3497
\end{aligned}
$$

\section{Discussion}

The linear relationships reported in Table 2 illustrate two important points. Firstly, there is not a simple one to two unit relationship between the $\mathrm{CS}(0-5)$ and $\mathrm{CS}(1-10)$ scales. Secondly, the relationship between the two systems varies during the year and/or pregnancy state. This indicates that a single calibration equation can not be universally used throughout the year when extrapolating data from one condition score scale to the other. Therefore if results from one system are to be used to interpret data in the other system the particular equation for that observation date must be used. Table 3 visually demonstrates the effect of the differing regression equations in Table 2 (ie, a 6 in the 1-10 systems can be equated to either a 2.5 or a 3.5 in the $0-5$ system depending on the time of year and/or pregnancy state) and provides an easy to use visual tool for both farmers and consultants when trying to convert condition score from one system to the other. Note that scores of 8 or higher in the $\mathrm{CS}(1-10)$ scale equate to 5 or greater on the CS(1-5) scale (except for pre calving

Table 1 Average cow liveweight $(\mathrm{kg})$ and condition scores using two scales at various times of the production cycle for Hereford $x$ Friesian cows (mean $\pm S E$ ).

\begin{tabular}{lcccc}
\hline Observation date & Number & Liveweight & CS $(1-5)$ & CS (1-10) \\
\hline Mid-winter 2001 & 219 & $450 \pm 3.23$ & $2.19 \pm 0.03(1.5-3.5)^{1}$ & $4.38 \pm 0.03(3.6-5.8)$ \\
Pre-calving 2001 & 219 & $471 \pm 3.32$ & $2.05 \pm 0.02(1.5-3.5)$ & $4.11 \pm 0.02(3.0-5.6)$ \\
Mating 2001 & 201 & $515 \pm 4.05$ & $2.70 \pm 0.05(1.0-4.5)$ & $4.78 \pm 0.04(3.0-8.4)$ \\
Weaning 2002 & 201 & $543 \pm 4.10$ & $2.75 \pm 0.10(1.0-4.5)$ & $4.88 \pm 0.04(2.5-7.8)$ \\
\hline
\end{tabular}

${ }^{1}$ Range of condition scores.

Table 2 Linear regression equations for the relationship between condition score $(0-5)$ and condition score $(1-10)$ at various times throughout the year.

\begin{tabular}{lllll}
\hline J une 2001 & $C S(0-5)=(0.823 \times C S 1-10)-1.41$, & $R^{2}=0.52$ \\
Pre-calving 2001 & $C S(0-5)=(0.239 \times C S 1-10)+1.06$, & $R^{2}=0.56$ \\
Mating 2001 & $C S(0-5)=(0.976 \times C S 1-10)-1.94$, & $R^{2}=0.65$ \\
Weaning 2002 & $C S(0-5)=(0.746 \times C S 1-10)-0.88$, & $R^{2}=0.57$ \\
All data & $C S(0-5)=(0.827 \times C S 1-10)-1.32$, & $R^{2}=0.59$ \\
\hline
\end{tabular}

Table 3 Calibration of the two scoring systems at various times of the

\begin{tabular}{|c|c|c|c|c|c|}
\hline $\begin{array}{c}\text { Condition } \\
\text { score }(1-10)\end{array}$ & Mid-Winter & $\begin{array}{l}\text { Conditio } \\
\text { Pre-calving }\end{array}$ & $\begin{array}{l}\text { score ( } \\
\text { Mating }\end{array}$ & $\begin{array}{l}-5)---- \\
\text { Weaning }\end{array}$ & All data \\
\hline 1 & -0.5 & 1.2 & -1.0 & -0.1 & -0.5 \\
\hline 2 & 0.2 & 1.5 & 0.1 & 0.6 & 0.3 \\
\hline 3 & 1.1 & 1.8 & 1.0 & 1.4 & 1.2 \\
\hline 4 & 1.9 & 2.0 & 1.9 & 2.1 & 2.0 \\
\hline 5 & 2.7 & 2.3 & 2.9 & 2.8 & 2.8 \\
\hline 6 & 3.5 & 2.5 & 3.9 & 3.7 & 3.6 \\
\hline 7 & 4.3 & 2.7 & 4.8 & 4.3 & 4.5 \\
\hline 8 & 5.1 & 3.0 & 5.8 & 5.0 & 5.3 \\
\hline 9 & 5.9 & 3.2 & 6.8 & 5.8 & 6.1 \\
\hline 10 & 6.8 & 3.5 & 7.8 & 6.6 & 7.0 \\
\hline
\end{tabular}
year based on regression equations in Table 2 . period) range perhaps indicating that the fatter beef cows were not being scored at the extreme when the dairy system was used.

From pre-calving (after adjustment for predicted weight of conceptus) through to weaning a difference of one condition score unit in the CS(1-10) and in the CS(1-5), respectively scale was equal to a change in liveweight $15 \mathrm{~kg}$ (weight change $=(14 \times \mathrm{CS})+$ $115, \mathrm{R}^{2}=0.12$ ) and $30 \mathrm{~kg}$ (weight change $=\left(26 \times \mathrm{CS}+82.6, \mathrm{R}^{2}=\right.$ 0.29 ). This result is for one year only but does compare favourably with published results of a $25 \mathrm{~kg}$ liveweight difference for one condition score unit change (using the 1-10 system) in Friesian and Jersey dairy cows (Macdonald \& MacMillian 1993). Knowledge of this relationship allows farmers to 
determine the feeding allowances required to increase CS by one unit in either system. The feeding requirements to increase liveweight by $1 \mathrm{~kg}$ has been known for some time (Nicol 1987).

The equations in Table 2 accounted for around 52$67 \%$ of the variation between the two CS systems. It is possible that skeletal differences inherent between dairy and beef cows (ie prominent pin bones) ensures the dairy operator using the CS(1-10) system places more emphasis on this and hence was not familiar to the more rounded (fatter) beef cows and scored much higher than the beef operator using the $\mathrm{CS}(0-5)$ scale.

\section{Conclusions}

The use of condition scoring in beef cow herds is to be encouraged and operators can use either scoring system. However this study indicates that the relationship between two different condition score systems varies during the year therefore care must be taken when interpreting data from publications using different scales. This study also demonstrates that an increase in liveweight of 15 and $30 \mathrm{~kg}$, respectively are required to increase condition score by one unit in the CS(1-10) and CS(1-5) systems.

\section{ACKNOWLEDGEMENTS}

The trial was funded by the Riverside Farm Research Fund, administered by Massey University.

\section{REFERENCES}

Corah, L.R. 1989. Body condition - an indicator of the nutritional status of beef cows. Agri-Practice 10:25-28.

DeRouen, S.M.; Franke, D.E.; Morrison, D.G.; Wyatt, W.E.; Coombs, D.F.; White, T.W. 1994. Prepartum body condition and weight influences on reproductive performance of first calf beef cows. Journal of Animal Science 72: 1119 - 1125.

Gilmour, M. 1998. Maximising efficiency/minimising loss. Beef breeding cow efficiency. Central Districts/ Wairarapa Region Beef Council Publication, Meat NZ.

Holmes, C.W.; Wilson, G.F.; MacKenzie, D.D.S.; Flux, D.S.; Brookes, I.M.; Davey, A.W.F. 1987. Milk production from pasture. Butterworths Agricultural Books, Wellington, pp29-31.

Jefferies, B.C. 1961. Body condition scoring and its use in management. Tasmanian Journal of Agriculture 32: 19-21.

Lowman, B.G.; Scott, N.A.; Sommerville, S.H. 1976.
Condition scoring of cattle. Bulletin East of Scotland College of Agriculture, No. 6.

Morris, C.A.; Cullen, N.G.; Carson, P.A.; Morley, G.A. 1985. Differences among and within crossbred beef cow groups in body condition and liveweight. Proceedings of the New Zealand Society of Animal Production 45: 167-169.

Morris, S.T.; Hughes, P.C. 1999. Management solutions for beef cows. Southern Region New Zealand Beef Council, Fox Glacier Field Day, Meat NZ.

MacDonald, K.A.; Macmillan, K.L. 1993. Condition score and liveweight in Jersey and Friesian cows. Proceedings of the Ruakura Farmers' Conference 45: 47-50.

Minitab 1998. Minitab version 12.1 Minitab Inc.

Nicol, A.M. 1987. Livestock feeding on pasture. New Zealand Society of Animal Production. Occasional Publication No. 10.

Nicoll, G.B. 1979. Influence of pre- and post-calving pasture allowance on hill country beef cow and calf performance. New Zealand Journal of Agricultural Research 22: 417 - 424.

Nicol, A.M.; Hughes, T.P. 1980. Nutritional requirements of the beef cow with particular reference to lactation. Proceedings New Zealand Veterinary Association Sheep and Beef Cattle Seminar, Lincoln College pp5670.

Reardon, T.F.; Welch, R.A.S.; Wright, D.E. 1978. Precalving nutrition of beef cows. Proceedings of New Zealand Society of Animal Production 38: 202 - 207.

Richards, M.W.; Spitzer, J.C.; Warner, M.B. 1986. Effects of varying levels of postpartum nutrition and body condition at calving on subsequent reproductive performance in beef cattle. Journal of Animal Science 62: 300 - 306.

Selk, G.E.; Wetlerman, R.P.; Lusby, K.S.; Oltjen, J.W.; Mobely, S.L.; Rasby, R.J.; Garmendia, J.C. 1988. Relationships among weight change, body condition and reproductive performance of range beef cows. Journal of Animal Science 66: 3153 - 3159.

Smeaton, D.C.; Bown, M.D.; Clayton, J.B. 2000. Optimum liveweight, feed intake, reproduction and calf output in beef cows on North Island hill country, New Zealand New Zealand Journal of Agricultural Research 43: 71-82.

Wright, I.A.; Russel, A.J.F. 1984. Partition of fat, body composition and body condition score in mature cows. Animal Production 38: 23-32. 